\title{
TURISMO Y TERRITORIO: ACTIVIDAD TURISTICA DE LA RESERVA NATURAL LAGUNA DE APOYO
}

\section{TOURISM AND TERRITORY: TOURIST ACTIVITY IN APOYO LAGOON NATURE RESERVE}

\author{
Berta Adilia Mena-García ${ }^{1}$ \\ Alfonso Blas Jirón-García ${ }^{2}$ \\ Universidad Nacional Autónoma de Nicaragua, Nicaragua
}

\section{RESUMEN}

Se estudia la Reserva Natural La Laguna de Apoyo, como un recurso turístico localizado en el municipio de Catarina, Departamento de Masaya, Nicaragua. Originada como producto de una portentosa erupción volcánica hace aproximadamente 23,00 años, posee una extensión es de 3,500 hectáreas. Sus componentes son la zona de amortiguamiento que comprende el valle de la laguna y la zona núcleo conformada por la laguna y laderas montañosas. Como recursos culturales se observan elementos conformados por: miradores, petroglifos, talleres de artesanía, jardines e iglesias. Los recursos naturales están constituidos por: la laguna, laderas cratericas, la flora y la fauna. Las actividades turísticas incluyen visitas a miradores, caminatas por los senderos, avistamiento de flora y fauna, natación, pesca, visitas a talleres y jardines y las fiestas religiosas. Como metodología para la obtención de la información se hicieron consultas bibliográficas, visitas comunitarias, aplicación de encuestas, entrevistas y guías de observación. Las encuestas se realizaron a turistas nacionales y extranjeros, y las entrevistas a líderes comunales y responsables de Instituciones. Los principales hallazgos la mayoría de turistas que visitaron la reserva son profesionales o estudiantes

1 Msc. en Geografía de la Población. Universidad Nacional Autónoma de Nicaragua, Nicaragua. Correo electrónico: adiliamena@gmail.com

2 Msc. en Investigación educativa. Universidad Nacional Autónoma de Nicaragua, Nicaragua. Correo electrónico: alfonsojir@hotmail.com 
Berta Adilia Mena-García, Alfonso Blas Jirón-García. Tourism and Territory: Tourist activity in Apoyo Lagoon Nature Reserve

universitarios, la laguna es la principal atracción de los turistas y según los encuestados la infraestructura turística de la reserva es muy buena.

Palabras clave: recurso turístico, zona de amortiguamiento, ecosistema.

\begin{abstract}
The Laguna de Apoyo Natural Reserve -located in the municipality of Catarina, Department of Masaya, Nicaragua is studied as a tourist resource. It originated as a result of a portentous volcanic eruption 23,00 years ago. Its area is 3,500 hectares. Its components are the buffer area comprising the valley of the lagoon and the core zone formed by the lagoon and mountain slopes. The resources of the Reserve are: lookouts, petroglyphs, craft workshops, gardens and churches. Natural resources include the Apoyo lagoon, slopes, flora and fauna. The tourist activities implemented are: visits to lookouts, hiking trails, sighting of flora and fauna, swimming, fishing, visits to workshops and gardens and religious holidays. To gather the information we did bibliographic consultations, visits to communities, implementation of surveys, interviews and observation guides. The surveys were applied to domestic and foreign tourists, and interviews were made to community leaders and heads of institutions. Among the relevant findings are the following: Most tourists visiting the reserve are professionals or university students, the lagoon is the main attraction for tourists, and according to surveys, tourists said that the tourism infrastructure of the reserve is very good.
\end{abstract}

Keyworks: tourist resource, buffer zone, ecosystem

\title{
1. Introducción
}

El turismo que se implementa en Nicaragua, está pasando por una posición muy ventajosa en el mercado regional e internacional, varias agencias de noticias como el New York Time, han clasificado a nuestro país, como el tercer destino turístico que se debe visitar, de una lista de 46 países.

Son varias las razones o criterios que se han tomado en cuenta para ubicarnos en esta posición privilegiada: los precios favorables de los hoteles, de las comidas y de los servicios básicos que convierten al país en un destino barato y competitivo; otra de las razones son las construcciones modernas que se están realizando, los hospedajes ecológicos y la sofisticada gastronomía. Todo esto se ha logrado por el esfuerzo conjunto del Gobierno, la Empresa Privada y las Cámaras de Turismo.

El país tiene mucho que ofrecer tanto en los recursos culturales como naturales y entre este último, sobresalen los parques nacionales y las reservas naturales. Uno de los recursos naturales mayormente visitado por su belleza escénica, es la Reserva Natural Laguna de Apoyo (RNLA), la que presenta variedad de elementos que permiten la promoción del agroturismo y el turismo ecológico entre otros. 
Para el estudio, se identificaron las diferentes actividades que se realizan en la reserva, al mismo tiempo se relacionaron con el estado actual de los ecosistemas, con el medio ambiente y con las actividades humanas que inciden de forma directa e indirecta en la zona estudiada. En el informe se hace relación a la metodología que se implementó para realizar el trabajo, a los aspectos físicos - geográficos de la reserva, a las partes que comprende el área protegida, a los recursos naturales y culturales que ofrece la zona y concluye con los resultados obtenidos derivados de las entrevistas realizadas a los turistas.

El estudio de la laguna de Apoyo reviste importancia porque intereso:

1. Identificar la situación ecológica que tiene la laguna como producto de la alteración de los bosques, el suelo y el agua.

2. Determinar el flujo turístico que incide en la RNLA para derivar el impacto que le ocasiona al medio ambiente.

3. Identificar los recursos de la zona con la finalidad de presentar algunas propuestas de explotación eco turísticas.

Con la investigación se persiguió :Identificar los diferentes componentes turísticos naturales y culturales que constituyen los elementos principales de la actividad turística que se realiza en la Reserva Natural Laguna de Apoyo(RNLA) con el objeto de que sean tomados como puntos de referencia para el diseño de proyectos turísticos que contribuyan al desarrollo de las comunidades locales.

\section{Área de estudio}

La RNLA se localiza entre los Departamentos de Masaya y Granada, esta bordeada por los siguientes Municipios: Catarina y San Juan de Oriente por el sector sur oeste; Diria y Diriomo por la parte sur; Granada colinda por el sector este y Masaya lo limita por la parte noroeste. 
Mapa 1. Nicaragua. Ubicación de la Reserva Natural Laguna de Apoyo

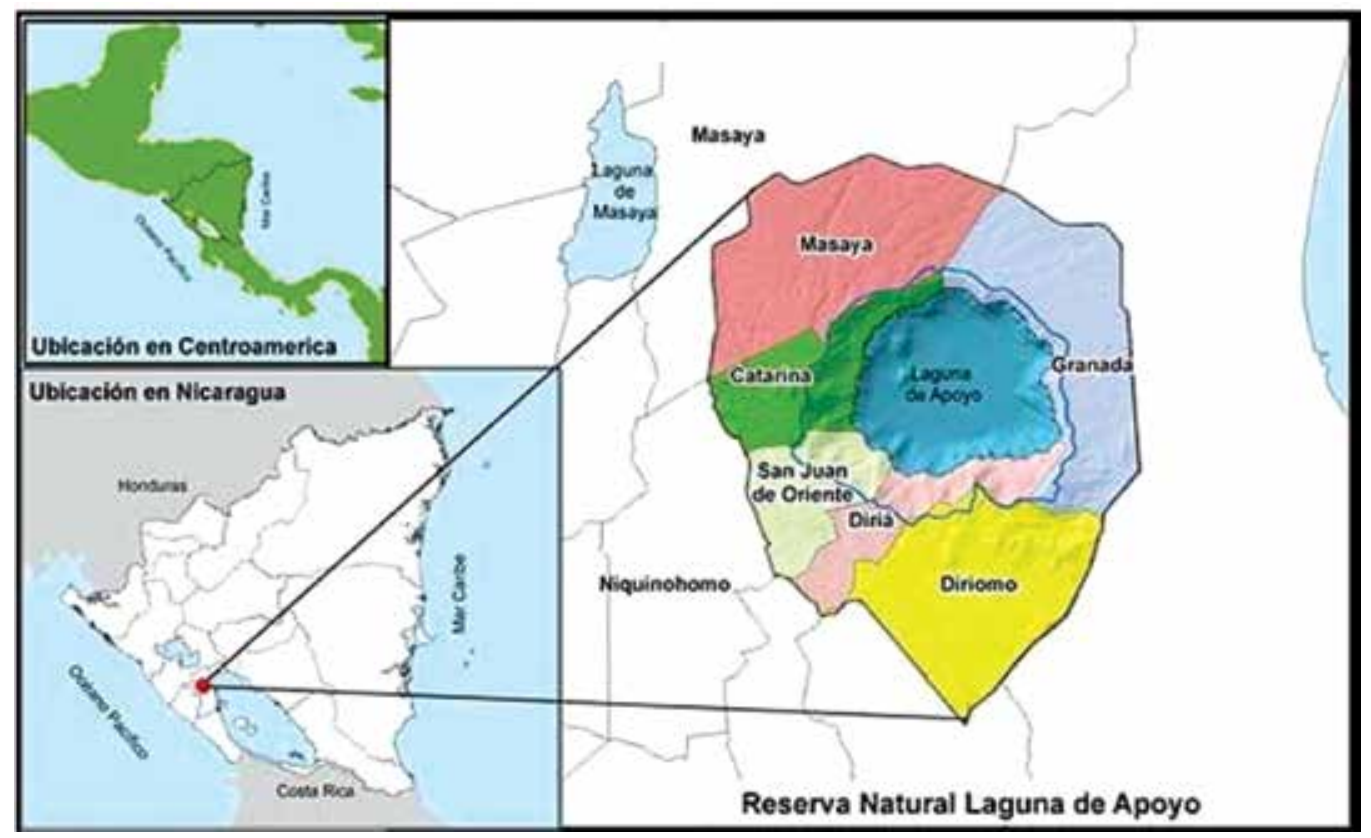

Fuente: MARENA.

La RNLA comprende una extensión de más de $123.53 \mathrm{~km} 2$, la superficie de la laguna está ubicada a $75 \mathrm{msnm}$.

El inmenso cráter volcánico de la Laguna de Apoyo, según estudios realizados, se formó hace aproximadamente 23000 años, después de una intensa y portentosa erupción arrojando gran cantidad de material piroclástico y piedras de basalto de grandes dimensiones.

Por la magnitud de la erupción, todo el cono volcánico fue arrojado hacia los sectores aledaños y en el fondo quedo una oquedad profunda, que con el tiempo, las condiciones climáticas y ambientales fueron rellenando de agua hasta formarse la laguna con laderas, cuyas alturas oscilan entre los 350 a 500 metros y en su mayoría cubierta de vegetación que dan albergue a una variedad faunística.

"El espejo de agua cristalina, azul y un poco salobre, tiene $6 \mathrm{~km}$ de diámetro. La caldera tiene forma circular, presentando laderas bajas y verticales en el sector este y otras más bajas y tendidas al oeste" (MARENA, 2009, p. 42). 
La combinación azul del agua de la laguna y las pendientes o laderas del cráter cubierto de una densa y verde vegetación, forman en su conjunto un paisaje natural que es motivo de atracción turística.

"El clima que presenta la reserva, es característico del trópico seco, sin embargo en las zonas altas (más de $400 \mathrm{msnm}$ ), el clima es de tipo pre montano, fresco y húmedo" (MARENA, 2009, p.41).

Las temperaturas son variadas: en la parte baja (según Salas 1993)," en las orillas de la laguna se registran temperaturas de $35^{\circ} \mathrm{C}$, mientras que en la parte alta en donde hay influencia del bosque y de los vientos, la temperatura es de $30^{\circ} \mathrm{C}$, con notables diferencia durante el periodo lluvioso y los meses de fin de año".

Las precipitaciones también son variadas, alcanzan un promedio de $1500 \mathrm{~mm}$ anuales.

\section{Características generales de la RNLA}

El 30 de Abril de 1998, la RNLA por decreto presidencial N 4291 se declara Área Protegida, la cual es cuidada y administrada por MARENA (Ministerio del Ambiente y Recursos Naturales), INTUR (Instituto Nicaragüense de Turismo), la Alcaldía Municipal y AMICTLAN, estas Instituciones ejercen control y vigilancia sobre los recursos naturales que existen en la reserva.

El área protegida (AP) comprende 2 zonas que están bien diferenciadas: El plan de la Laguna o Zona de Núcleo y la Zona de Amortiguamiento. 
Berta Adilia Mena-García, Alfonso Blas Jirón-García. Tourism and Territory: Tourist activity in Apoyo Lagoon Nature Reserve

Mapa 2. Nicaragua. Municipios que bordean la Reserva Natural Laguna de Apoyo.

\section{ZONA NÚCLEO DE LA RNLA}
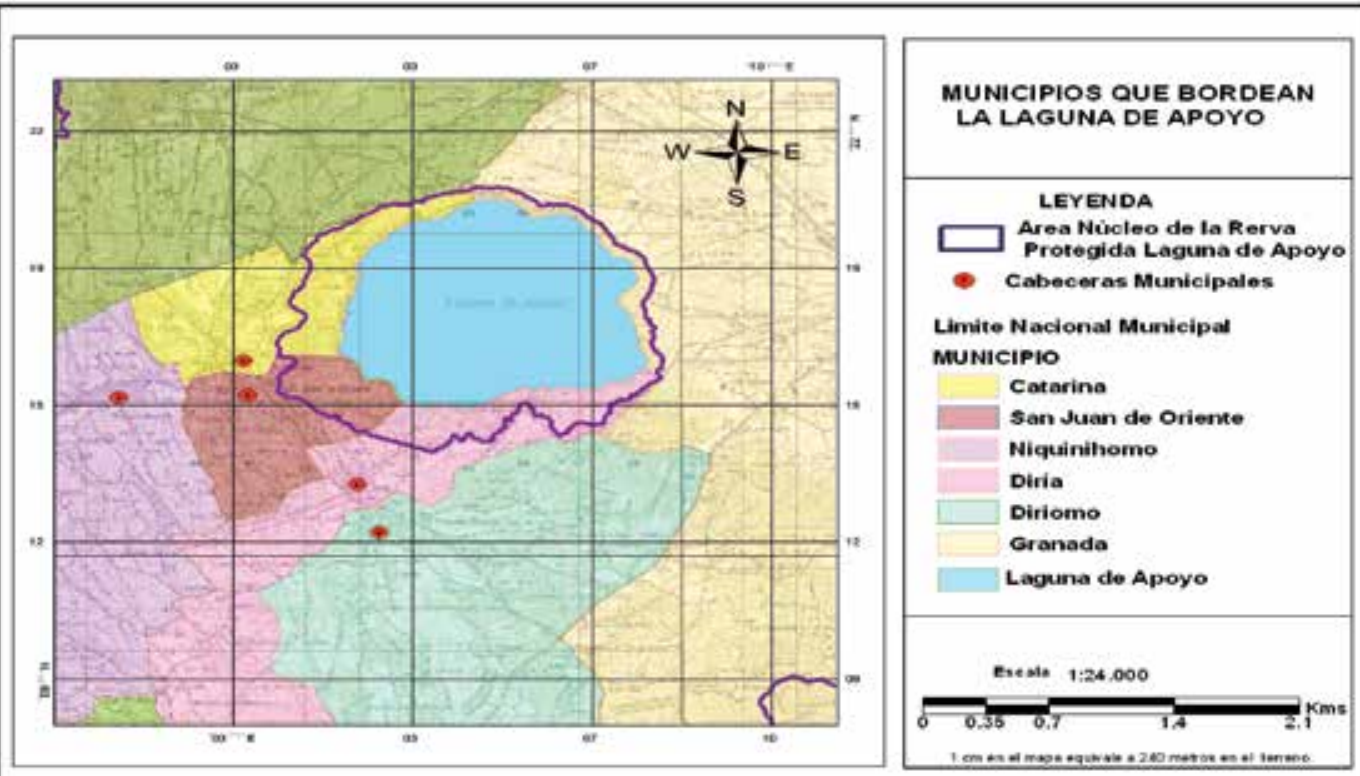

Fuente: Elaboración propia.

La zona núcleo es donde se encuentra la laguna, en sus orillas se han establecido varios hoteles, hospedajes, restaurantes y residencias veraniegas considerándose esta zona como una de las más explotadas. Las laderas montañosas resguardan al cráter, por tanto es la zona central o principal que es objeto de conservación por las Instituciones encargadas.

"La laguna constituye la masa acuosa que ocupa el fondo del cráter volcánico, es de forma circular. La superficie del agua mide $21.1 \mathrm{~km}^{2}$, su profundidad alcanza los 200 metros y su diámetro es de $6 \mathrm{~km}$. Entre las lagunas crátericas de Nicaragua, la de Apoyo es la más grande en superficie, profundidad y en volumen de agua" (MARENA, 2009, pág. 86).

"Las aguas son salobres, alcalinas y con altas concentración de sílice por lo que no son aptas para el consumo humano. Su fauna está representada por peces como la tilapia y mojarras, pero además tiene especies 
endémicas que no se encuentran en otras partes del mundo tales como: la mojarra flecha, la mojarra costera, la mojarra chancho y la mojarra pequeña" (MARENA, 2009, p. 63).

Las costas de la laguna están limitadas por las estribaciones de las laderas y en la mayoría de los casos no alcanzan los $10 \mathrm{~m}$; en el sector de los hoteles y los restaurantes, las costas han sido alteradas por las construcciones, limitando el espacio para la recreación de los veraneantes.

En el área adyacente a la costa, se ha producido un acelerado crecimiento urbanístico, proliferando los hoteles de categoría como el Apoyo Resort, (antes Norome) y el de La Abuela, hay hospedajes populares, bares, restaurantes y casas de verano. Esta es una de las áreas humanizada de la laguna y es la que está provocándole severos daños por la concentración de basura y la ocupación y alteración de las costas.

Las laderas son los bordes montañosos que rodean al cráter las que están cubierto de vegetación nativa, hasta la fecha están levemente alteradas porque han sido objeto de despale en algunas zonas

Las laderas presentan abundante material piroclástico con estratos de pómez y grandes rocas basálticas que por los sismos se desprenden fácilmente desde las alturas hasta el plan de la laguna. Los terrenos de las laderas son frágiles y la erosión ha producido deslaves, hondonadas y grandes cárcavas.

El ecosistema terrestre que se encuentra en las laderas está conformado por un bosque del trópico seco y en algunos sectores que presentan alta pluviosidad, tienen la transición hacia el bosque húmedo.

En los sectores donde existe mayor concentración de bosques todavía se puede advertir el predominio de especies faunísticas como: los venados, monos congos, monos cara blanca, cusucos y gran variedad de aves.

Las especies representativas de la flora son: cedro, laurel, mora, ñambaro, etc. En la actualidad hay programas de reforestación con árboles nativos, como: guapinol, cedros y frutales. Cerca del municipio de San Juan de Oriente hay fuentes de aguas termales, las que constituyen evidencias de una incipiente actividad volcánica.

Las laderas de la laguna están expuestas a diferentes procesos que le provocan inestabilidad: hay constantes precipitaciones, se usan de manera no adecuada los suelos, se hacen construcciones y se talan los árboles que dejan como resultado la exposición de los suelos a la erosión y al deslave. 
A todo esto se le agrega la ocurrencia de sismos, que son los causantes del desprendimiento de grandes rocas basálticas que llegan hasta la orilla de la laguna. Las evidencias de este fenómeno se puede observar a los largo de la carretera que conduce hacia la laguna.

Imagen 1. Rocas Basálticas.

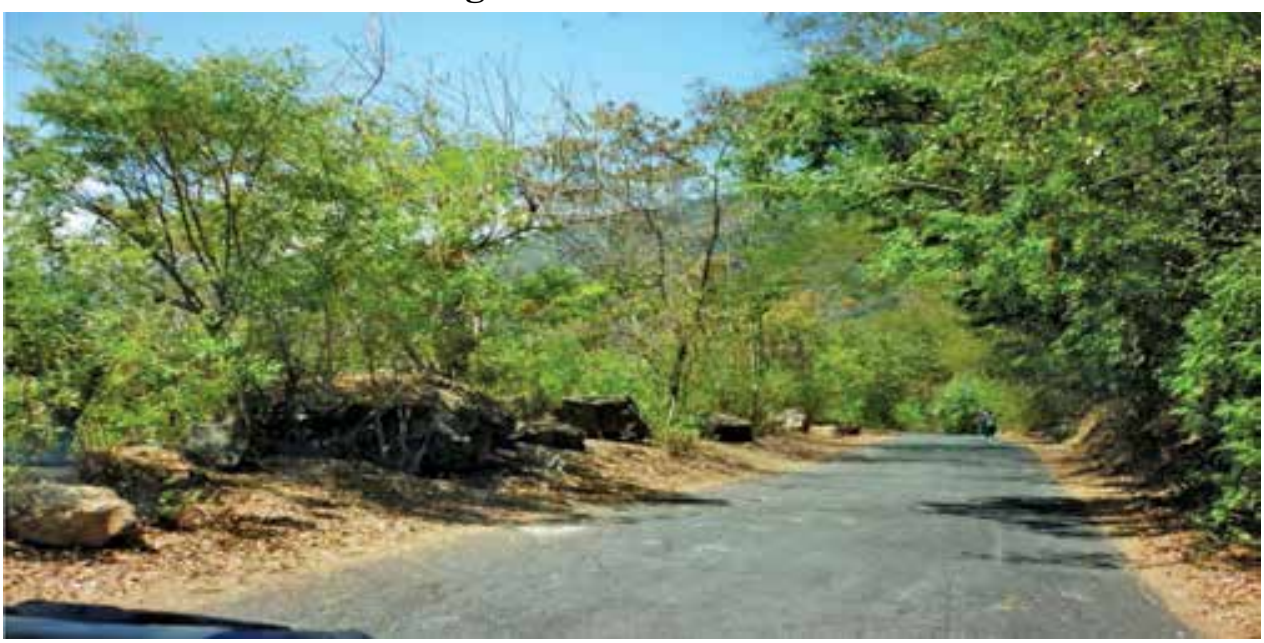

Fuente: Propia.

La zona de amortiguamiento es el sector localizado en los alrededores del cráter y es donde se encuentran pequeñas pero pintorescas ciudades, que por sus características homogéneas se les denomina "Los pueblos blancos". Además se localizan numerosas comarcas, cuyos habitantes se dedican a labores artesanales y a la agricultura.

En esta zona existen algunos elementos que le son característicos: Es la zona más amplia de la reserva y en el borde cráterico, están concentrado los Pueblos Blancos (Catarina, Diria, Diriomo y San Juan de Oriente) los que presentan miradores hacia la laguna. 
Mapa 3. Nicaragua. Municipios que bordean la Reserva Natural Laguna de Apoyo.

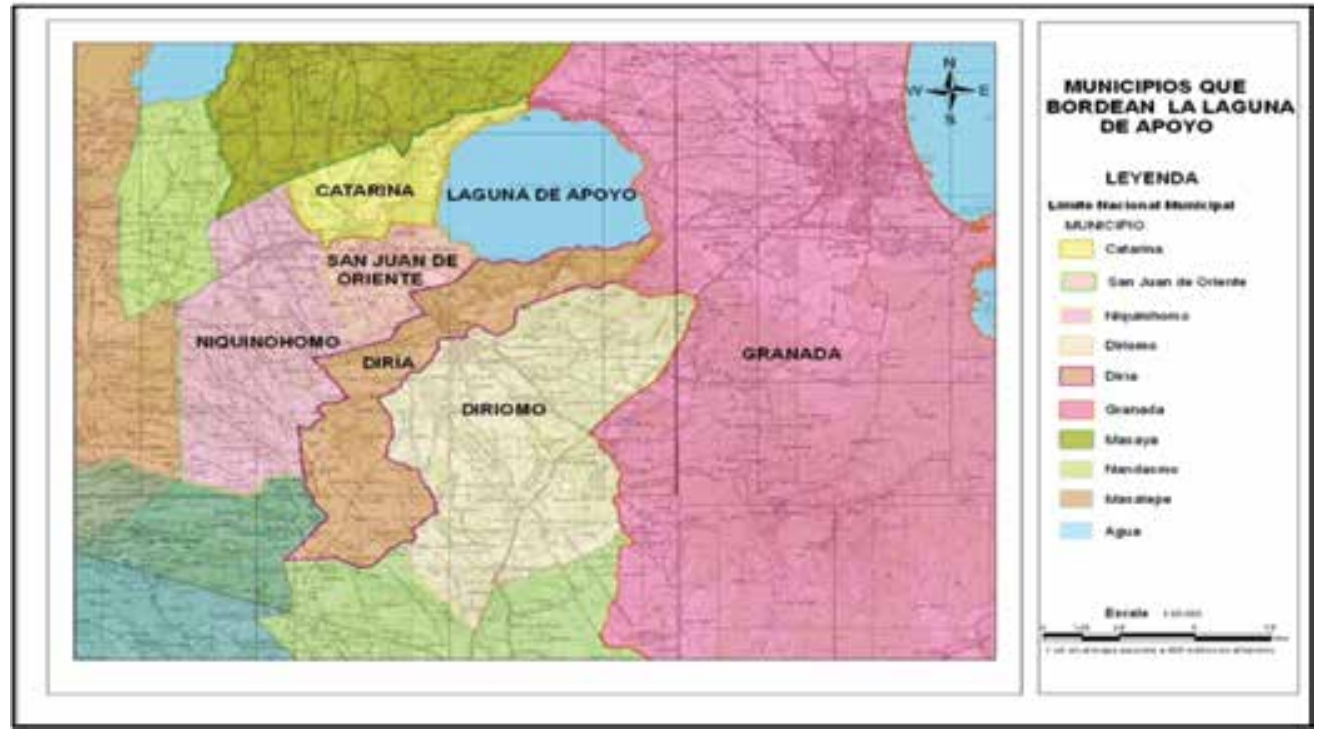

Fuente: Elaboración propia.

- $\quad$ En las comarcas ubicadas en la zona de amortiguamiento, se encuentran cantidades de talleres artesanales que en su mayoría están integrados por los miembros de la familia: trabajan la madera preciosa elaborando muebles finos y rústicos, hacen adornos típicos; con la fibra de bambú diseñan canastos, petates y alfombras y además elaboran variedad de vasijas y adornos de barro.

- La población por las características de las actividades laborales que realizan, son los que ejercen gran presión sobre los recursos naturales del área protegida principalmente en las laderas y las costas.

En el sector occidental de la laguna, ocupado por las ciudades de Catarina, San Juan de Oriente, Diria, Diriomo y todas sus comarcas, se observa gran parte de la estructura habitacional de la población como casas, hoteles, restaurantes, talleres, así como los diversos caminos y senderos que atraviesan los bosques de las laderas hasta llegar a la laguna. 
En la zona de amortiguamiento existe un sector semiplano que concentra mucha población, a este lugar se le denomina el Valle de la laguna localizándose en la parte nor-occidental.

El Valle se ubica en la parte media, es decir, en la zona aledaña al borde craterico y está conformado por terrenos que se prolongan hacia el interior de la zona de amortiguamiento. Los campesinos que habitan estos territorios, son dueños de pequeñas parcelas de tierras y en ellos cultivan maíz, arroz, frijoles, tubérculos como yuca y quequisque, también cultivan plantas ornamentales y de flores pero lo que más sobresalen son los cultivos de frutales como los jocotes, mangos, marañones y cítricos, los que son comercializados en gran escala en los mercados municipales de Masaya, Granada y Managua.

Imagen 2. Área de cultivo en la zona de amortiguamiento

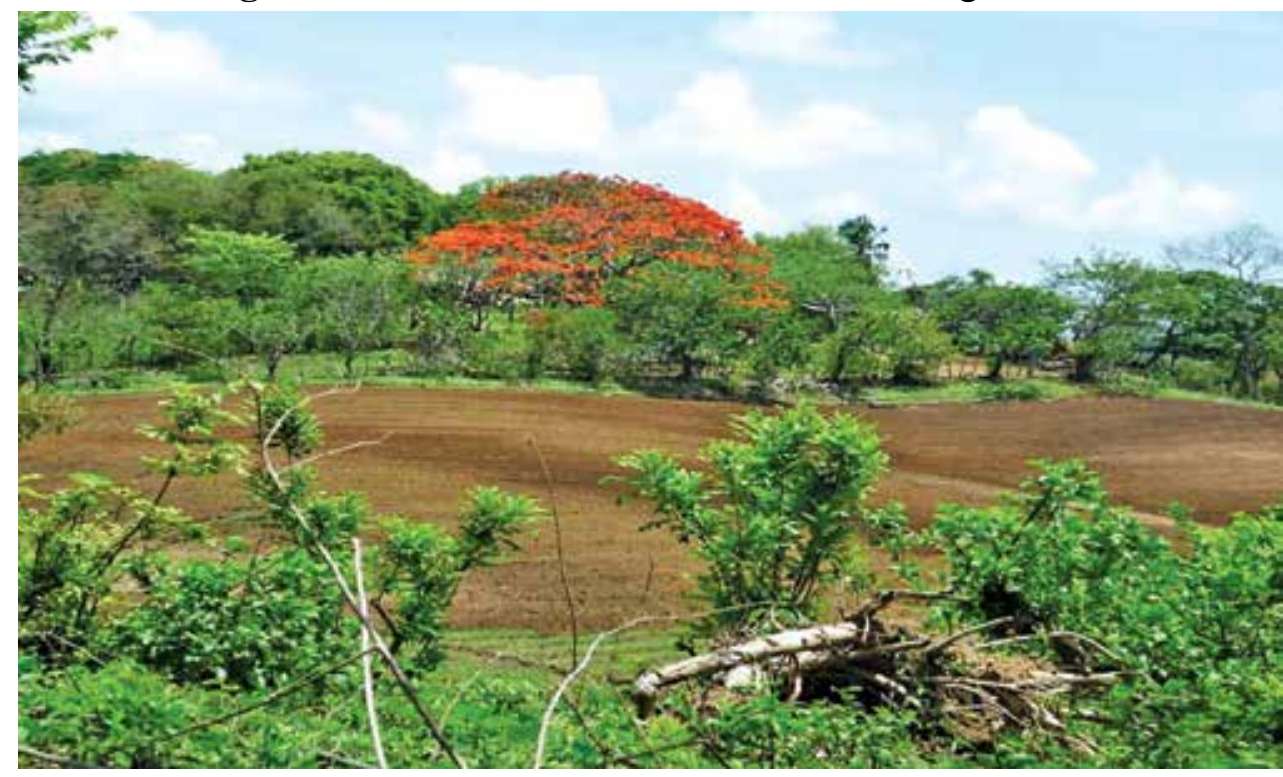

Fuente: Propia.

El borde craterico que se encuentra en el Valle está representado por la orillas de las alturas de las laderas y en ellas hay muchos sitios en donde se pueden observar los más bellos paisajes que presenta la laguna, la vegetación y las pendientes de las laderas, de manera que en algunas de 
estas localidades, estos lugares han sido acondicionados como Miradores porque contienen los mejores sitios paisajísticos.

\section{- $\quad$ Los recursos naturales y culturales de la RNLA.}

La RNLA posee en su territorio una gran variedad de recursos naturales y culturales los que son objeto de admiración y de explotación racional para el aprovechamiento sostenible.

Los recursos naturales que tiene la reserva están constituidos por los siguientes componentes: la Laguna de Apoyo que constituye la principal atracción turística, las altas pendientes de los bordes cratericos localizadas en todo el contorno de la laguna, los bosques de trópico seco que contiene variedad de árboles y plantas nativas y la diversidad de fauna terrestres, arbórea y acuática.

Los recursos culturales están conformados por los miradores que el hombre ha acondicionado para que se pueda apreciar y admirar la belleza paisajística que presenta la laguna desde cualquier ángulo; los petroglifos que se encuentran distribuidos en varias localidades; los talleres artesanales en donde se producen muebles, adornos y petates con características precolombinas, las iglesias aunque pequeñas pero tienen un carácter neo clásico y colonial; los viveros de plantas ornamentales que provocan mayor vistosidad a las ciudades.

\section{Actividades Turísticas en la Reserva}

La actividad turística que se realiza en la reserva es variada debido a la diversidad de recursos naturales y culturales que tiene el área protegida. En la reserva se realizan las siguientes actividades:

- Visita a los miradores establecidos en Diriá, Catarina y Pacaya. Los miradores se encuentran en el borde de la caldera y ofrecen un paisaje espectacular. En ellos se admira la belleza del paisaje, se pueden realizar caminatas a pie o a caballos para recorrer los diferentes senderos cubiertos de exuberante vegetación.

- $\quad$ Realización de picnic en las costas de la laguna. Por lo general las familias durante los fines de semana bajan a la laguna, se instalan en un sitio, preparan alimentos, almuerzan y se bañan en las frescas aguas. 
- Realización de caminatas por los diferentes senderos que hay en las laderas, esto permite que el turista tenga un contacto más directo con la naturaleza, que admire la flora y la fauna, es decir, que practique el ecoturismo.

- $\quad$ Avistamiento de aves, mamíferos y reptiles, el propósito es disfrutar de la fauna que ofrecen los ecosistemas.

- $\quad$ Práctica de la natación, del buceo, la pesca deportiva, el uso de los pequeños botes de remo y también del kayak.

- $\quad$ Practicas del turismo de aventura, el cual consiste en subir y bajar las altas pendientes de las laderas.

- $\quad$ Práctica de parapente en donde jóvenes aficionados desafían las alturas y adquieren destrezas y habilidades en este deporte.

- Visitas a los talleres artesanales, para apreciar las destrezas de los trabajadores en la elaboración de muebles y adornos elaborados con el barro, la madera y las fibras.

Imagen 3. Artesanías de Los Pueblos Blancos.

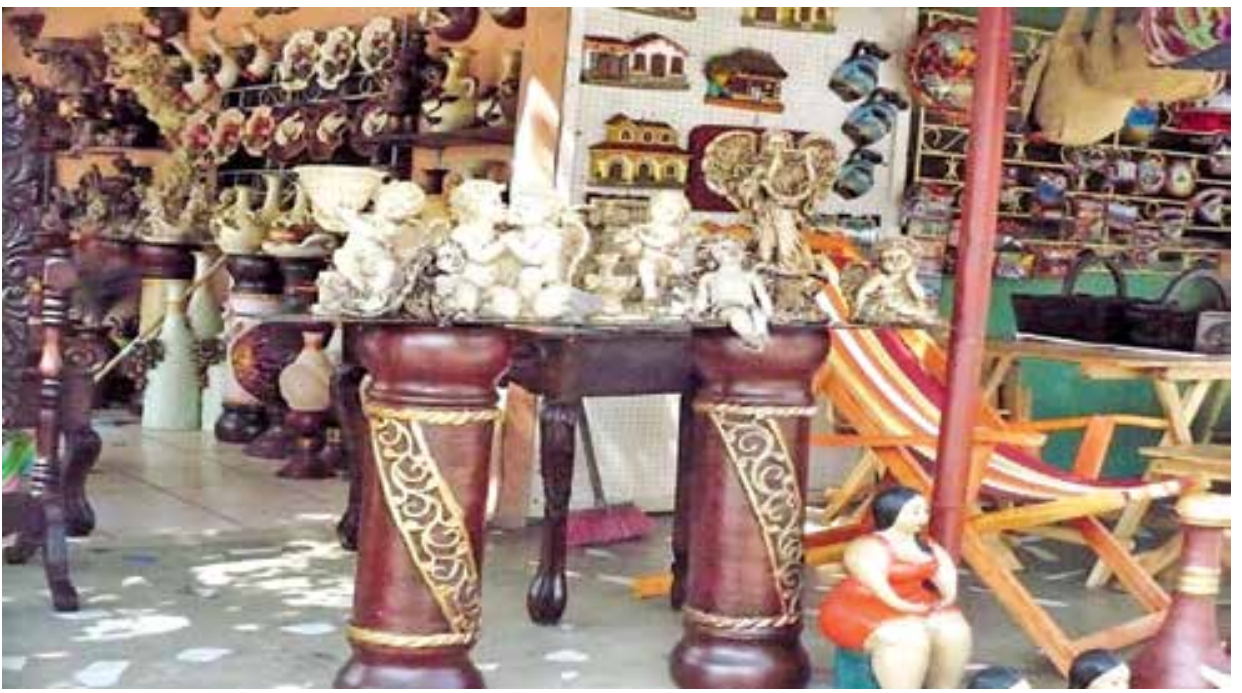

Fuente: Propia.

- Visita a los viveros y jardines en donde se pueden admirar las bellezas de las flores y las plantas las que se pueden adquirir a precios módicos. 
- Visitas nocturnas o durante el día a los hoteles y restaurantes de la localidad con fines recreativos.

- Visita a cada uno de los Pueblos Blancos para participar en las celebraciones religiosas que se realizan durante las fiestas patronales, que se distinguen por sus tradiciones y costumbres.

- $\quad$ Los tipos de turismo que se pueden implementar son: El Turismo Ecológico en toda el área de las laderas, esto es posible por el tipo de bosque y la variedad de fauna; el Turismo de Aventura, que se puede practicar en esa misma zona; en la propia laguna se puede implementar el Turismo Sol Playa, el Turismo de Deporte Acuático y el Turismo de Contemplación Paisajística. En las ciudades se puede implementar el Turismo Religioso, el Turismo de los Talleres artesanales y el de los Viveros.

\section{Marco metodológico}

La Reserva Natural Laguna de Apoyo, se localiza en la parte sur del departamento de Masaya, compartiendo su espacio con el departamento de Granada.

Fueron autores de la investigación, los líderes de las diferentes comunidades aledaños a la laguna, las alcaldías, algunas ONG's que tienen presencia en las comunidades, los turistas y la población en general. La investigación se desarrolló en las siguientes etapas:

1. Recopilación de datos cartográficos y su correspondiente mapeo.

2. Aplicación de instrumentos: encuestas entrevistas y guías de observación.

3. Elaboración de matrices de investigación en donde se concentró toda la información recopilada.

4. Procesamiento de la información utilizando el programa SPSS.

5. Análisis de los datos obtenidos y la elaboración del informe de la investigación.

El tipo de investigación es de tipo descriptiva porque se pretendió con ella la medición de la actividad turística que se realiza en la zona de estudio. En relación a los métodos utilizados durante el estudio se procedió de la siguiente manera: DEDUCTIVO en su primera fase porque se buscó toda la información bibliográfica que nos aseguró las bases teóricas 
que sirvieron de sustento a la investigación, pero también se usó el método INDUCTIVO cuando se realizaron reiteradas visitas a la reserva y se pudo obtener información la que fue registrada en las respectivas bitácoras.

Durante el levantamiento de la información se utilizaron encuestas las que fueron aplicadas a los pobladores de las comunidades, se realizaron entrevistas a los turistas nacionales y extranjeros, a los líderes comunales y a los representantes de algunas instituciones estatales y privadas.

Para la realización del estudio se tomaron dos tipos de poblaciones: La primera está conformada por los representantes de las organizaciones estatales y ONG's, y la segunda población estuvo integrada por los turistas nacionales y extranjeros.

En relación a la primera población, se hizo un muestreo no probalístico y de tipo intencional o dirigido seleccionándose a las personas que reunieron los requisitos o criterios establecidos por los investigadores, como por ejemplo ser los responsables de las instituciones.

Para la segunda población, al igual que la anterior, se utilizó el muestreo no probabilístico y de tipo casual porque se abordaron a los turistas que estaban en el área protegida o que ya la habían visitado. Para la realización del análisis de la información se tomó como puntos de partida las matrices de investigación, procediendo de la manera siguiente:

1. Elaboración de tablas de frecuencia, las que se diseñaron de acuerdo a los aspectos relevantes del estudio y con la utilización del SSPS.

2. Se diseñaron gráficos donde se reflejan los datos relacionados al comportamiento del fenómeno estudiado.

3. Con las tablas de frecuencias y los gráficos se procedió a realizar el análisis respectivo de las variables más incidentes en el estudio.

4. Se hizo una presentación textual de los principales resultados que reflejan el estudio realizado.

5. Para la información textual se complementó con la utilización de los mapas los que dan mayor credibilidad y confianza al estudio.

\section{Resultados}

Para la obtención de la información sobre los aspectos relevantes de la actividad turística que se implementa en la RNLA, se realizaron 130 
entrevistas a los visitantes, teniendo presente que de preferencia fueran turistas extranjeros y que hubieran visitado la reserva.

Los aspectos relevantes de las entrevistas son:

\section{- Lugar de residencia.}

Para la investigación fue muy importante indagar sobre el lugar de residencia de los visitantes porque de esa manera se pudo conocer su procedencia. Los resultados fueron los siguientes: El 21.80\% de los turistas manifestaron proceden de Europa, destacándose los países como España, Italia y Suecia. El 20.30\% señalo que proceden de Costa Rica; el 19.55\% de los turistas expreso que vinieron de los Estados Unidos y el15.79\% de los entrevistados dijeron que son turistas nacionales.

Figura 1. Nicaragua. Reserva Natural Laguna de Apoyo. Lugar de residencia de los visitantes. 2015.

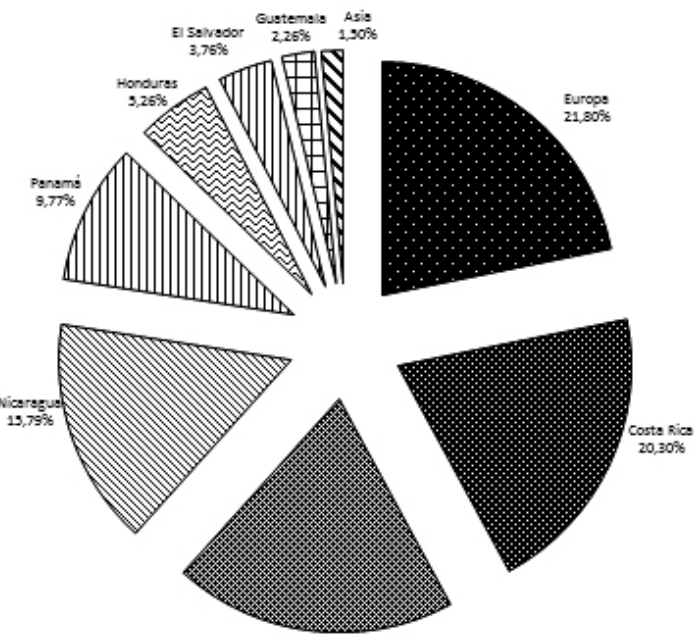

Fuente: Entrevista realizada a los visitantes, 2015.

\section{- $\quad$ Edad de los turistas.}

El aspecto relacionado a la edad de los turistas también resulto de mucho interés, debido a que refleja el segmento poblacional que constantemente visita la reserva. Los resultados señalan lo siguiente: el $23.31 \%$ de los turistas expresaron que tienen edades que oscilan entre los 20 y 25 
años, mientras que otro grupo, es decir el $23.31 \%$ señala que sus edades están comprendidas entre los 26 y 30 años. Se encontró que el $15.04 \%$ de los entrevistados presentan edades de más de 51 años, así mismo el 12.78 $\%$ de los visitantes tienen edades entre los 31 y 35 años, finalmente se encontró que el $10.53 \%$ de los turistas están comprendidos en el rango de edades de 36 a 40 años.

A manera de síntesis, se señala que la mayoría de los visitantes, el $69.93 \%$ son personas jóvenes con edades que oscilan entre los 20 y 40 años.

Figura 2. Nicaragua. Reserva Natural Laguna de Apoyo.

Edad de los turistas. 2015.

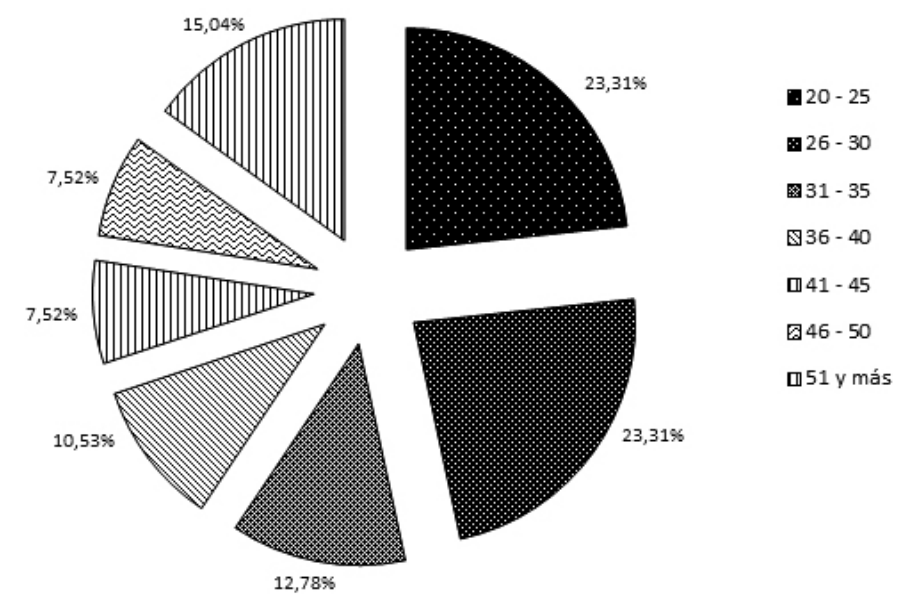

Fuente: Entrevista realizada a los visitantes, 2015.

\section{Ocupación de los turistas}

El perfil ocupacional de los turistas es indispensable conocerlo para la promoción de la oferta turista que se debe impulsar en la RNLA. Al realizar las entrevistas, se obtuvieron los siguientes resultados: El 45.86\% de los visitantes son profesionales graduados en diferentes carreras universitarias, el $24.81 \%$ están empleados en la rama de los servicios y el $21.80 \%$ son estudiantes universitarios. Todo estos resultados reflejan que el $77.66 \%$ de los entrevistados son estudiantes universitarios o son profesionales graduados. 
Figura 3. Nicaragua. Reserva Natural Laguna de Apoyo. Ocupación de los turistas, 2015.

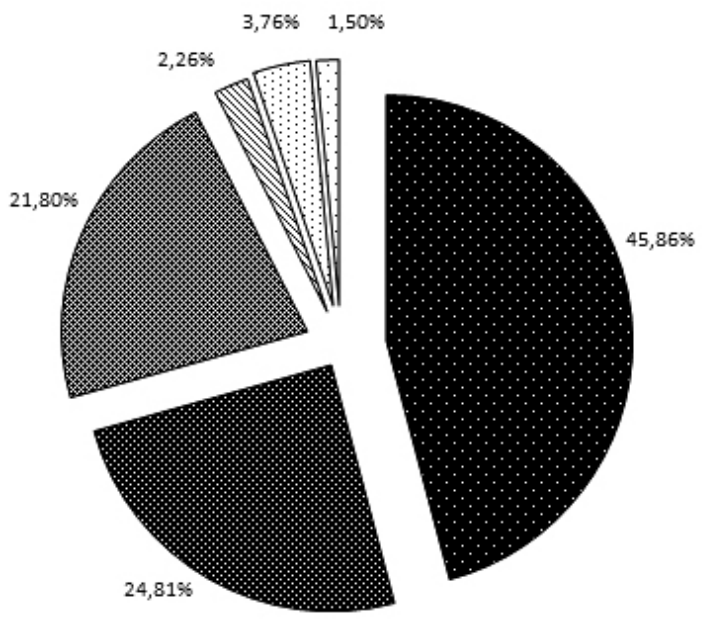

- Profesionales

Servicios

图Estudiantes

SArtesanos

BOtros

¿No respondió

Fuente: Entrevista realizada a los visitantes, 2015.

\section{- $\quad$ Porque medio de transporte ingreso a Nicaragua.}

Para los efectos de la mercadotecnia es importante conocer los medios de transporte que utilizan los turistas para llegar al país. Al realizar la entrevista, los datos señalan que: El 45.11\% lo hacen utilizando transporte terrestre, esta modalidad es la que utilizan los turistas centroamericanos principalmente los que proceden de Costa Rica y el 39.10\% viajan a Nicaragua empleando el transporte aéreo, esto, está referido a los visitantes cuya procedencia es Europea o de los Estados Unidos. Del total de los datos el $13.53 \%$ de los turistas no respondieron. 
Figura 4. Nicaragua. Reserva Natural Laguna de Apoyo. Medio de transporte por el que ingresó a Nicaragua, 2015.

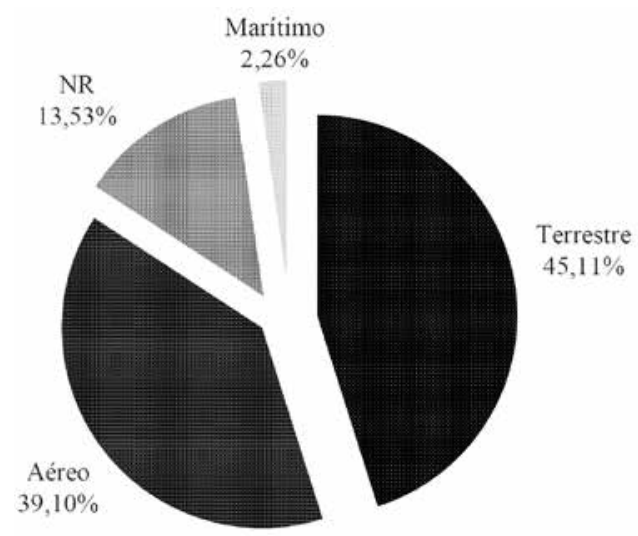

Fuente: Entrevista realizada a los visitantes, 2015.

\section{- La RNLA es el destino principal de los turistas.}

Al preguntarle a los turistas si la RNLA constituye su principal destino, la información proporcionada, señala que: el $75.19 \%$ de los turistas manifestaron que sí, que visitar la laguna era su destino principal y el restante $23.31 \%$ expresaron que no, porque ya la habían visitado en otras ocasiones. Estas afirmaciones vienen a reafirmar que la laguna de Apoyo constituye un foco de atracción turístico.

Figura 5. Nicaragua. Reserva Natural Laguna de Apoyo. Destino principal de los turistas, 2015.

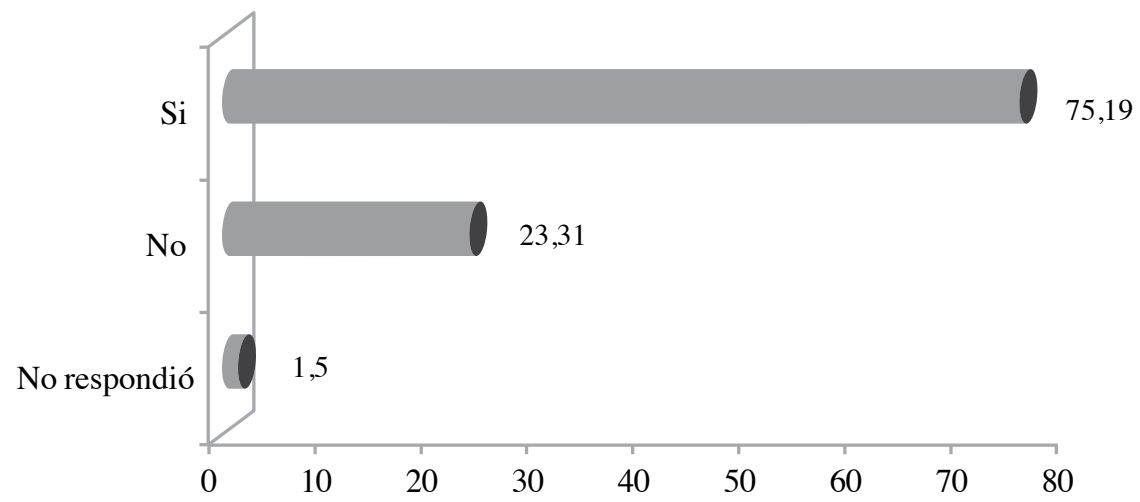

Fuente: Entrevista realizada a los visitantes, 2015. 


\section{- Como supo de la existencia de la RNLA.}

Esta pregunta es muy importante por cuanto permitió conocer los medios a través de los cuales se divulgo la existencia de la RNLA. Los datos señalan: El 56.39\% expresaron que conocieron de la existencia del lugar por las personas que en otras oportunidades ya la habían visitado. El $18.05 \%$ manifestaron que el conocimiento lo obtuvieron al consultar las guías turísticas; el $12.07 \%$ respondieron que supieron de la existencia del lugar a través de internet mientras que el $12.78 \%$ expresaron que lo hicieron por otra vía aunque no la especificaron.

Figura 6. Nicaragua. Reserva Natural Laguna de Apoyo. Medio por el cual se enteró de la existencia de la RNLA, 2015.

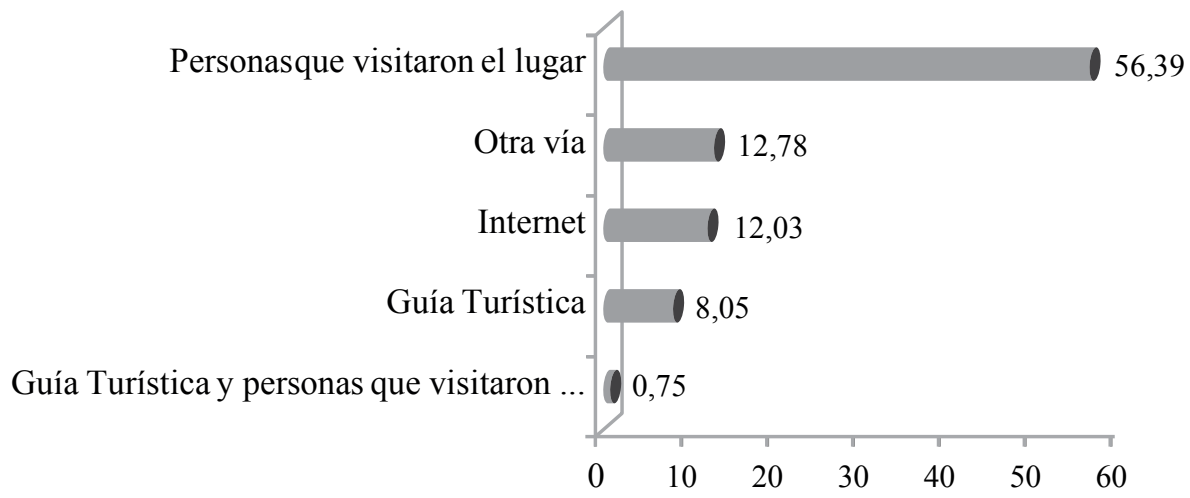

Fuente: Entrevista realizada a los visitantes, 2015.

\section{- $\quad$ El gasto promedio de los turistas.}

La actividad turística que se realiza en el país está en crecimiento, para ello era necesario conocer la cantidad de dinero que gasta el turista. Por las entrevistas realizadas se obtuvieron los siguientes resultados: El $63.91 \%$ manifestaron que gastan como promedio una cantidad que oscila entre los 50 y 75 dólares, el $18.80 \%$ expresaron que tienen un gasto mayor de 100 dólares, el 10.53\% dijeron que gastan entre 76 y 100 dólares. 
Figura 7. Nicaragua. Reserva Natural Laguna de Apoyo.

Gasto promedio de los turistas, 2015.

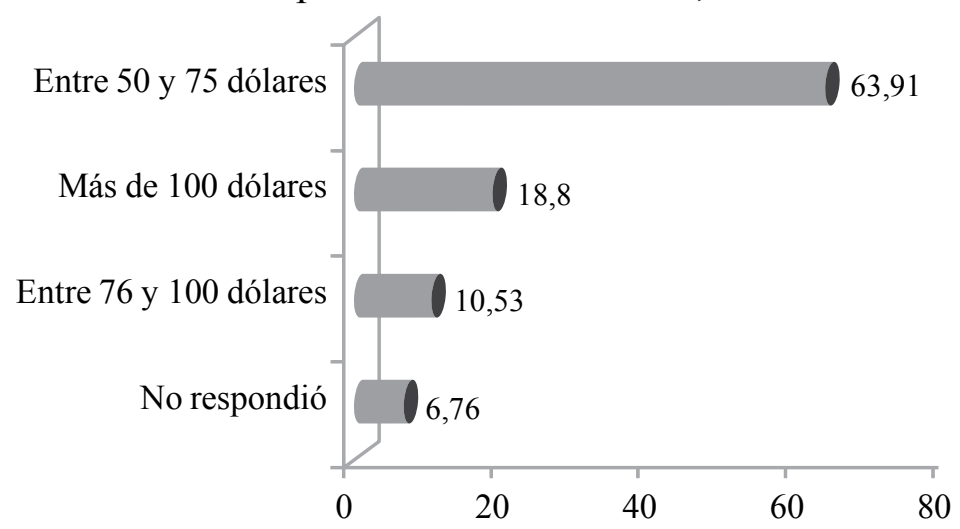

Fuente: Entrevista realizada a los visitantes, 2015.

- Beneficios del turismo a la economía y a la población.

También resulto muy interesante consultar si la actividad turística deja beneficios a la economía y por ende a la población La respuesta afirmativa fue indicada en un $98.5 \%$ mientras que el restante $1.50 \%$ opinó lo contrario.

Figura 8. Nicaragua. Reserva Natural Laguna de Apoyo. Beneficios del turismo a la economía y a la población, 2015.

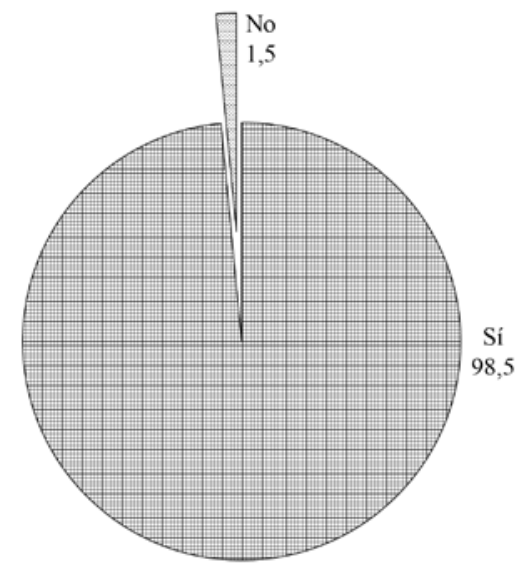

Fuente: Entrevista realizada a los visitantes, 2015. 


\section{- Calidad de los servicios turísticos que se ofertan en la RNLA.}

Este aspecto es muy interesante porque con las respuestas se obtiene un indicador valioso que permite evaluar la calidad de los servicios ofertados. Las respuestas indican que el $42.11 \%$ manifestó que los servicios son de muy buena calidad, el $39.85 \%$, lo evaluaron como bueno y el $17.29 \%$ lo catalogaron como excelente. Estos niveles de respuestas revelan resultados muy satisfactorios y constituyen un elemento motivador para el impulso de la actividad turística en la laguna de Apoyo.

Figura 9. Nicaragua. Reserva Natural Laguna de Apoyo. Calidad de los servicios turísticos que se ofertan en la RNLA.

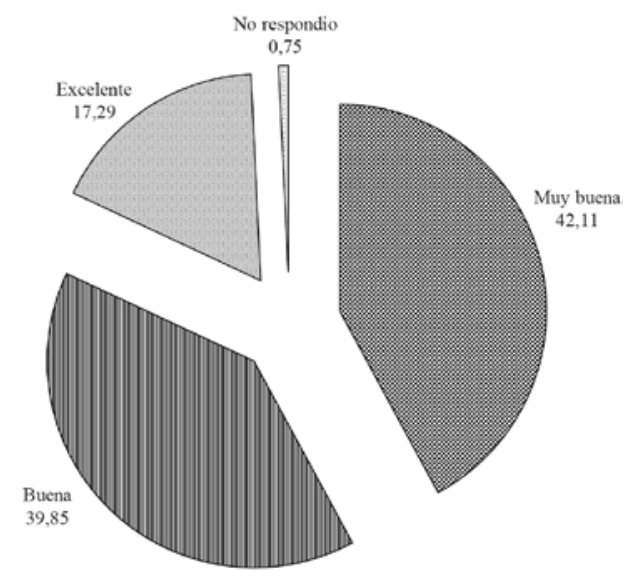

Fuente: Entrevista realizada a los visitantes, 2015.

\section{Conclusiones}

La RNLA constituye un gran potencial turístico: la laguna y las laderas internas del cráter albergan un importante ecosistema terrestre.

El bosque trópico seco, está siendo severamente afectado por el uso que de ellos hace la población, por la reducida protección de las instituciones encargadas y por la débil implementación de los planes de manejo.

El ecosistema acuático lacustre de la RNLA, es oligotrófico y ligeramente salino, es especial por la transparencia de sus aguas. La presencia de varias especies endémicas de peces en la laguna y las que evolucionaron dentro de esta, la convierten en un punto de gran valor para la biodiversidad y por tanto se le debe otorgar alta prioridad y protección continua a los hábitats. 
No existen condiciones de recreación masiva dada la fuerte pendiente de la costa y la profundidad de las aguas.

La zona de amortiguamiento es la que concentra la mayor cantidad de población, principalmente en el sector occidental.

Los terrenos estatales son pocos, en su mayoría han sido vendidos por los gobiernos municipales de turno, tanto a particulares como a extranjeros quienes desean construir residencias e infraestructura modernas.

La falta de control sobre los negocios de carácter turísticos afectan los ecosistemas poniendo en grave peligro a las especies florísticas y faunísticas.

La RNLA, es un sitio que tiene un valioso potencial turístico y además es un lugar muy importante por su flora y fauna, por la laguna, por la producción artesanal y agrícola, por las costumbres de sus pobladores y por sus tradiciones religiosas.

\section{Recomendaciones}

A continuación, se proponen una serie de recomendaciones dirigidas a las instituciones estatales y privadas, a las alcaldías y a la población en general.

- $\quad$ Que el Plan de Manejo del MARENA de la RNLA se aplique y a su vez que se regulen las nuevas construcciones habitacionales en la reserva.

- Se debe fomentar el turismo ecológico para que se conserven los ecosistemas con todos sus componentes, es decir los recursos naturales y el medio ambiente.

- $\quad$ Para los sitios deforestados debe impulsarse un plan de reforestación involucrando a los pobladores de las diferentes comunidades en donde se promueva la siembra de especies nativas. 


\section{Referencias}

AMICTLAN - GM (2009): Estudio socioeconómico de la Reserva Natural Laguna de Apoyo y su zona de Amortiguamiento. Programa integral por el ordenamiento ambiental de apoyo (PIXOA). Ed. Fundación - ACCD AMICTLAN - GM, Catarina, Nicaragua.

Ley 217 (1996). Ley General del Medio Ambiente. La Gaceta. Managua, Nicaragua.

Luque, M. y Siles, G. (2011). Potencial Turístico del Municipio de Catarina y el Rol del Gobierno Municipal para Fortalecer el Desarrollo Local. Monografía. Managua, Nicaragua.

Meyrat, S. (2007). Programa Para la Gestión Ambiental Integral y Sostenible de la Laguna de Apoyo en Nicaragua. Estudio Dinámica Espacial y Temporal de Cobertura y Uso de La Tierra en la RNLA. Managua, Nicaragua.

MARENA. (2009). Plan de manejo de la Reserva natural de la Laguna de Apoyo (Ministerio del Ambiente y de los Recursos Naturales). Masaya, Nicaragua.

Miranda, M. (2007). Actividades Productivas y la Tenencia de la Tierra en la Laguna de Apoyo, monografía del Dpto. de Geografía. Managua, Nicaragua. 